\title{
Qual o melhor momento para a abertura de capital?
}

\section{Palavras-chave}

IPO, opções reais, programação dinâmica

\section{Classificação JEL}

C61, D92, G10

Keywords

IPO, real options, dynamic programming

\section{JEL Classification}

C61, D92, G10

\footnotetext{
* Professora Associada da Faculdade de Economia e do Programa de Pósgraduação em Economia Aplicada da Universidade Federal de Juiz de Fora fernandafinotti.

** Professor do Instituto de

Administração e Gerência da

Pontifícia Universidade Católica do

Rio de Janeiro

*** Mestre em Economia pelo

Programa de Pós-graduação em

Economia Aplicada da Universidade

Federal de Juiz de Fora
}

\section{Resumo}

Para algumas empresas de capital fechado, a questão não é se ela deve abrir ou não o capital, mas sim quando, ou seja, qual o momento mais apropriado (timing) para realizar a abertura de capital. Nesse contexto, o presente trabalho teve por objetivo verificar se as decisões de Initial Public Offering (IPO) das empresas brasileiras de energia que realizaram IPOs durante o período 2000-2009 (quais sejam: CPFL, EDP, Cosan, Brasil Ecodiesel, São Martinho, Açúcar Guarani, MPX e OGX) foram determinadas (ou tomadas) segundo descrito pelo modelo de Draho (2000), o qual se baseia na Teoria das Opções Reais (TOR). Como resultado, encontrou-se que todas as empresas estudadas anteciparam o timing da sua oferta em relação ao preconizado pelo modelo de Draho.

\author{
Fernanda Finotti Cordeiro Perobelli ${ }^{\star}$ \\ Luiz Eduardo Teixeira Brandão** \\ Taiany Abreu Soares ${ }^{* * *}$
}

\section{Abstract}

For some private companies, it is not a question of why go public, but rather what is the most appropriate time to conduct an IPO. In this context, this study aimed to verify if IPO decisions taken by eight Brazilian energy companies (CPFL, EDP, Cosan, Brasil Ecodiesel, São Martinho, Açúcar Guarani, MPX and OGX) during the period 2000-2009 were based on an IPO timing model developed by Draho (200o), following the Real Options approach. As a result, we found that all the companies studied have anticipated their IPO timing related to Draho's model estimates. 


\section{1_Introdução}

A primeira venda de ações ${ }^{1}$ de uma empresa no mercado acionário é a oferta pública inicial, usualmente referida como IPO (do inglês Initial Public Offering). Quando esse evento ocorre, as empresas "abrem" seu capital, transferindo aos investidores parte do seu controle acionário, o que lhes permite participar do processo de tomada de decisões e/ou de usufruir de parte dos lucros da empresa (dividendos ou juros sobre capital próprio). Em troca, as companhias de capital aberto recebem capital para seus investimentos, podendo, então, expandir seus negócios e aumentar sua participação nos mercados em que atuam.

As principais razões abordadas pelas teorias tradicionais sobre estrutura de capital ${ }^{2}$ para justificar a abertura de capital são que o IPO é uma opção de financiamento mais barata para algumas empresas (a depender do conjunto de características dessas empresas); que a governança corporativa trazida pela estrutura de propriedade pública minimiza os conflitos de agência; 3 que a transparência trazida pela publicidade de informações estratégicas da empresa aumenta o valor de mercado dessa e que a reestruturação societária pode gerar mais liquidez (acesso a fontes de financiamento) para a empresa. Entretanto, para algumas empresas de capital fechado, a questão não é se ela deve abrir ou não o capital, mas sim decidir qual o melhor momento (timing) de fazê-lo, uma vez que a concretização das vantagens apresentadas pelas teorias de estrutura de capital depende não apenas da existência de um mercado acionário desenvolvido, mas também da existência de janelas de oportunidade que reduzam os custos indiretos de colocação. ${ }^{4}$

Alguns estudos se propuseram a analisar o melhor momento (timing) para se realizar o IPO estimando a decisão de abrir o capital através da Teoria das Opções Reais (TOR). Tal teoria serve bem a esse propósito se for considerado que o gestor da empresa de capital fechado, a cada período, toma uma decisão binária, irreversível e instantânea que maximiza sua riqueza: continuar operando com a empresa, ou seja, receber o fluxo de lucro imediato mais os lucros futuros esperados ou vender participação no capital da empresa a investidores externos (realizar o IPO), recebendo, em troca, determinado valor de venda. Como existem incertezas sobre o valor futuro da empresa, tem-se uma opção real de timing que é valiosa, já que o gestor sempre poderá esperar por situações de mercado mais favoráveis antes de abrir o capital da empresa.

Sob essa perspectiva, Draho (2000) foi o primeiro autor a desenvolver um modelo de avaliação do timing do IPO que faz uso de duas premissas básicas: (1) mercado incompleto, em que se supõe que o proprietário inicial (empreendedor) concentra toda a sua riqueza na empresa possuindo riscos privados (diversificáveis) e sistêmicos (não diversificáveis), enquanto os investidores externos diversificam seus investimentos e carregam apenas riscos sistêmicos e (2) eficiência informacional, da qual se deriva que somente as informações públicas sobre o lucro médio do setor, disponíveis no mercado, são relevantes para a decisão de realização do IPO, e, assim, a assimetria de informação é desconsiderada. Nesse modelo, existe uma única variável que causa incerteza sobre o valor da empresa, que é o fluxo de lucros futuros. Essa incerteza é modelada pelo processo estocástico denominado movimento geométrico browniano5 (MGB).

Em seguida, Bouis (2003) aprimora o modelo anterior, acrescentando, na abordagem do timing, os investidores otimistas, que carregam divergências nas crenças sobre o valor da empresa. Neste modelo, ganha destaque a questão do alto desempenho das ações no mercado secundário no curto prazo (underpricing), seguida de reversão (baixo desempenho) no longo prazo. No modelo de Bouis (2003), existem duas fontes de incerteza: o valor da empresa, determinado 
pelo fluxo de lucros futuros, e o preço das ações no mercado secundário em momento posterior ao IPO, estabelecido pelo número de investidores otimistas. Essas incertezas são modeladas, respectivamente, por meio do processo estocástico MGB e do processo misto de Poisson-Wiener.

O objetivo deste trabalho é verificar se as decisões de IPO das empresas brasileiras de energia que realizaram seus IPOs durante o período 2000-2009 foram determinadas (ou tomadas), segundo descrito pelo modelo de Draho (2000). Optou-se por analisar empresas do setor de energia pelo fato de elas terem buscado o mercado acionário como alternativa de financiamento com frequência no período analisado. Quanto ao período de análise, a escolha se deu por ter havido, a partir de 2004, no mercado acionário brasileiro, aumento significativo no número de IPOs (com 0 ano de 2007 sendo caracterizado como um hot market). Esse movimento, entretanto, foi desacelerado pela crise do subprime ocorrida no final de 2008.

O artigo está estruturado da seguinte forma: a seção 2 apresenta o referencial teórico sobre os modelos de timing do IPO. A seção 3 aborda a metodologia e a descrição operacional das variáveis utilizadas. A seção 4 mostra a aplicação das técnicas e os resultados obtidos. A seção 5 apresenta as considerações finais do trabalho.

\section{2_Referencial teórico: modelos de timing do IPO}

Draho (2000) inicia seu trabalho sobre timing de IPOs constatando dois fatos ocorridos no mercado acionário americano durante a década de 1990. O primeiro é que, geralmente, as aberturas de capital ocorrem após um aumento anormal no índice de mercado da indústria. $\mathrm{O}$ segundo destaca que as ações emitidas, em média, apresentam baixo desempenho, ou seja, retorno abaixo do esperado no longo prazo. Essas observações combinadas levaram o autor a concluir que os gestores das empresas são capazes de explorar informações sigilosas, observando no mercado janelas de oportunidades temporárias. Seu modelo é construído sobre as oito premissas seguintes, sendo a principal delas a premissa quatro (mercado incompleto), flexibilizada no modelo de Bouis (2003):

1. A empresa é criada no tempo $t=0$, com um custo inicial de $I_{0}$, custeado pelo empreendedor (dono da empresa), que é avesso ao risco e conduz a decisão da empresa de abrir ou não o seu capital. Além dos custos iniciais e dos custos operacionais necessários e implícitos, não há nenhum investimento adicional. Em seguida, a empresa gera um fluxo de lucro $\pi_{t}^{p}$ a partir de um nível de lucro inicial $\pi_{0}{ }^{p}$, onde o subscrito " $p$ " indica que a empresa ainda é privada.

2. O tempo evolui continuamente, e, a qualquer momento após $t=0,0$ empreendedor pode vender $\alpha$ participações no capital da empresa ao mercado acionário. Essa venda do patrimônio a investidores externos não gera quaisquer distorções sobre o fluxo de lucros, e a fração $0<\alpha<1$ das ações a serem vendidas aos acionistas é determinada exogenamente. Isso porque a emissão potencial das ações não é motivada por exigências de capital (para investimentos ou modificações na estrutura de capital da empresa), ou seja, o empreendedor não possui dívidas e não necessita de capital para operar a empresa.

3. A oferta pública inicial é irreversível e instantânea (a fração $\alpha$ é vendida integral e instantaneamente).

4. O empreendedor concentra toda a sua riqueza na empresa, possuindo riscos privados 
(diversificáveis) e sistêmicos (não diversificáveis) e utilizando uma taxa de desconto $\left(\rho^{p}\right)$ que o remunera pelos dois riscos. Por outro lado, os investidores externos diversificam seus investimentos e carregam apenas riscos sistêmicos, possuindo uma taxa de desconto $\left(\rho^{m}\right)$ que os remunera apenas pela parcela sistêmica do risco. Assim, a taxa de desconto do empreendedor deve ser maior que a taxa de desconto do mercado, que, por sua vez, deve ser maior que a taxa média de crescimento dos lucros (PIB) da indústria $\mu,{ }^{6}$ que também deve ser maior que a taxa livre de risco r, portanto, $\rho^{p}>\rho^{m}>\mu>r$ (premissa de mercado incompleto).

5. As informações assimétricas e os fatores estratégicos não são levados em consideração no modelo, uma vez que, ao decidir realizar o IPO, o empreendedor deve proporcionar aos potenciais acionistas informações sobre a situação geral da empresa (sinal). Essas informações são usadas pelos investidores externos para estimar o valor da empresa a partir do valor de empresas similares. Para eliminar qualquer interação estratégica entre os agentes econômicos, é assumido que o sinal é perfeitamente revelador (premissa de eficiência informacional).

6. Os lucros da empresa são altamente correlacionados com o lucro (PIB) médio do setor $\left(\pi_{t}\right)$. Além disso, os lucros são simetricamente distribuídos em torno do lucro médio do setor. Assim, o empreendedor e os potenciais acionistas compartilham das mesmas incertezas em relação aos lucros futuros. Na TOR, para modelar as incertezas, defini-se o processo estocástico que rege a variável de incerteza. No modelo proposto, os lucros futuros deverão crescer a uma taxa constante $\mu$ (crescimento) e serão afetados pelos mesmos fatores externos de risco (volatilidade) $\sigma$, tais como a ameaça de potenciais concorrentes e o desenvolvimento de novas tecnologias que levem à existência de novos produtos. Tem-se que a incerteza sobre lucros futuros pode ser modelada através do processo estocástico conhecido como movimento geométrico browniano, dado por

$\frac{d \pi_{t}}{\pi_{t}}=\mu d t+\sigma d z$

onde $\mu$ é a média da taxa de crescimento do lucro do setor, $\sigma$ é a volatilidade, $d t$ é a grandeza da variação do tempo e $d z$ é o processo de Wiener: $7 d z=\varepsilon_{t} \sqrt{d t}$ e $d z \sim \mathrm{N}(0, \sqrt{d t})$. Com isso, partindo de um nível inicial de lucro $\pi_{0}^{p}$, os investidores saberão qual é o nível de lucro $\pi_{t}^{p}$ da empresa em qualquer $t$, simplesmente, usando a equação do processo estocástico.

7. O conjunto de informações recebido pelo mercado sobre o lucro de empresas homogêneas é aleatório. Ao longo do tempo, o valor que os investidores externos conferem à empresa também é aleatório, seguindo o mesmo processo estocástico do lucro médio do setor. Além disso, os investidores externos possuem a mesma aversão ao risco, já que utilizam as mesmas informações de mercado. Assim, conseguem valorizar a empresa de capital fechado de maneira simétrica. De modo similar, pelo lado do empreendedor, como os fluxos futuros de lucros são incertos, a valorização que esse atribui à própria empresa também segue o MGB. Tem-se que tanto o empreendedor quanto os investidores externos 
valorizarão a empresa por:

$v^{i}\left(\pi_{t}\right)=\frac{\pi_{t}}{\delta^{i}} i \in\{m, p\}$, onde $\pi_{t}$ é o lucro médio

do setor e $\delta^{i}=\rho^{i}-\mu$. Como as incertezas sobre os lucros futuros decorrem estritamente de alterações nas condições do mercado, ambas as valorizações feitas pelos agentes seguem o mesmo processo estocástico do lucro, ou seja, o MGB.

8. Quando abre seu capital, o empreendedor incorrerá em custos de emissão. Esses custos apresentam-se de duas formas: despesas diretas $\mathrm{C}$ (que englobam taxas, despesas legais e outras despesas administrativas) e comissões de subscrição $\lambda$ cobradas sobre o valor da emissão pelo subscritor (underwriter), o que deixa $(1-\lambda)$ do valor emitido para o empreendedor. Por outro lado, o empreendedor receberá um valor bruto pela venda das participações no capital igual a $\alpha \frac{\pi_{t}}{\delta^{m}}$, o que gera um valor líquido de receita do IPO dado pela seguinte equação:

$$
\Omega\left(\pi_{t}\right)=\alpha \frac{\pi_{t}}{\delta^{m}}(1-\lambda)-C .
$$

Para resolver o problema de timing, o autor explica que, pelas premissas anteriores, o valor de mercado da empresa será maior que o valor privado, pois $\delta^{m}<\delta^{p}$. Com isso, $v^{m}>v^{p}$. Assim, o IPO deveria ser imediatamente realizado. Entretanto, como há custos de emissão e incertezas sobre o fluxo de lucros futuros, existe uma imprecisão em escolher o melhor momento, já que o empreendedor pode esperar por situações melhores de mercado. Essa indecisão faz com que a flexibilidade gerencial do timing seja valiosa, pois, uma vez tomada a decisão de abrir o capital, o empreendedor exerce a opção, e o seu valor é perdido. Por isso, o valor da opção de timing é considerado como um custo de oportunidade do IPO. Dessa maneira, o empreendedor enfrenta duas alternativas e deverá escolher aquela que maximiza sua riqueza: continuar a receber o fluxo de lucro imediato mais os lucros futuros esperados ou realizar o IPO, recebendo determinado valor líquido de venda das ações em troca.

$\mathrm{Na}$ circunstância em que se tem um ativo real comercializável que não possui no mercado um ativo financeiro replicável (venda das participações no capital da empresa, por exemplo) e ainda existe a premissa de mercado incompleto, a melhor técnica de otimização sob incerteza a ser utilizada é a programação dinâmica. Nesse caso, Dixit e Pindyck (1994) explicam que continuar (ou manter a empresa privada) pode gerar um fluxo de lucro positivo ou negativo, e, por outro lado, parar (ou vender parcelas da empresa numa operação de IPO) pode gerar um valor residual (payoff terminal), devendo o empreendedor escolher o melhor momento de mudar a situação da empresa (de privada para pública) com vistas a maximizar seus ganhos totais.

Baseando-se nessa técnica, o autor encontra o valor máximo da empresa para o empreendedor, considerando a op-

ção de timing: $F(\pi)=A_{1} \pi^{\beta_{1}}+\alpha \frac{\pi}{\delta^{p}}$. Essa equação possui dois componentes: $A_{1} \pi^{\beta_{1}}$, que é o valor da opção de fazer o IPO ${ }^{8}$ a qualquer momento, e $\alpha \frac{\pi}{\delta^{p}}$, que é o valor privado da empresa.

Ao considerar a opção de timing, a empresa realiza a abertura de capital quando o valor líquido da venda das participações do capital for suficientemente maior que o valor privado que o empreendedor atribui à empresa mais o valor da opção de timing do IPO, ou seja, quando ocorrer um aumento anormal do preço no mercado. Portanto, o 
empreendedor realizará a abertura de capital da sua em-

presa quando $\underbrace{\alpha \frac{\pi}{\delta^{m}}(1-\lambda)-C}_{\Omega(\pi)}-\underbrace{\frac{\alpha \pi}{\delta^{p}}-A_{1} \pi^{\beta_{1}}}_{F(\pi)}>0$. A partir

disso, Draho (2000) encontra determinado nível crítico de lucro $\left(\pi^{*}\right)$ que induz o empreendedor a abrir o capital. Uma vez observadas as condições de mercado, as incertezas e os custos do IPO, esse nível de lucro crítico maximiza a riqueza do empreendedor. A seguir, tal modelo é apresentado em detalhes.

Considerando que o valor de uma empresa com opções reais aumentará de acordo com o grau de flexibilidade gerencial e nível de incerteza sobre o valor da empresa, como o dono da empresa sempre pode esperar por melhores condições de mercado antes de abrir o capital, a opção de timing é valiosa e deve ser considerada junto com o valor privado que o empreendedor tem da empresa. Pela modelagem da TOR, tem-se:

Valor daempresa $a_{\text {EXPANDIDO }}=$ Valor daempres $a_{\text {TRADICIONAL }}+$ + Valor daopção $o_{\text {FLREXIBILIDADEGERENCIAL }}$

A decisão do empreendedor de abrir o capital da empresa é determinada pela comparação do valor das ações privadas da empresa com os rendimentos esperados do IPO. Na metodologia da TOR, o IPO vai ocorrer somente quando o valor líquido da venda das participações no capital for suficientemente maior que o valor privado que o empreendedor tem ao manter a empresa fechada, mais o valor da opção de realizar o IPO (timing). A escolha que o empreendedor fará é maximizar sua riqueza através da seguinte escolha:

a) continuar operando a empresa (mantendo a opção viva), caso em que a riqueza do empreendedor é dada pelos lucros atual e futuros trazidos a valor presente pela taxa de desconto do empreendedor

$$
\left(\rho^{p}\right): \alpha \pi_{t} d t+\frac{1}{\left(1+\rho^{p} d t\right)} E[F(\pi+\pi d t) / \pi],
$$

b) parar de comandar a empresa, realizando o IPO e obtendo $\Omega(\pi)$.

Pela técnica de programação dinâmica, a equação de Bellman, ${ }^{9}$ no modelo de Draho (2000), assume a seguinte forma:

$$
\begin{aligned}
& F\left(\pi_{t}\right)= \\
& =\max \{\underbrace{\alpha \pi_{t} d t+\frac{1}{\left(1+\rho^{p} d t\right)} E\left[F\left(\pi_{t}+\pi_{t} d t\right) / \pi_{t}\right]}_{\text {continuar }}, \underbrace{\Omega\left(\pi_{t}\right)}_{\text {parar }}\}(1)
\end{aligned}
$$

Para solucionar a equação acima, faz-se a derivação em duas etapas (Dixit; Pindyck, 1994; Draho, 2000): a primeira é feita através do fluxo de lucro determinístico, caso em que o empreendedor é considerado como ingênuo (naive) ou míope, uma vez que não considera a opção de timing, e, assim, qualquer benefício associado a um período de espera é ignorado $(\sigma=0)$. A segunda etapa é feita por meio do fluxo de lucro estocástico, caso em que há incerteza sobre o fluxo de lucro $(\sigma>0)$, e, assim, tem-se a flexibilidade de esperar o melhor momento para abrir o capital da empresa. Nesse caso, é considerada a possibilidade de uma sequencia de choques positivos no lucro durante um curto período de tempo de espera, o que torna a opção atrativa.

Na primeira derivação, mediante o fluxo de lucro determinístico, iguala-se a equação (1) ao valor privado das ações da empresa, ou seja, $\alpha \frac{\pi^{n}}{\delta^{m}}(1-\lambda)-C=\alpha \frac{\pi^{n}}{\delta^{p}}$. A intuição é que o empreendedor abrirá o capital da empresa, assim que os recursos líquidos do IPO forem maiores que a valorização das ações privadas da empresa, assumindo 
que elas manterão o mesmo valor para sempre. Resolvendo para $\pi^{n}$, encontra-se o seguinte nível de lucro crítico ingênuo (naive):

$$
\pi^{n}=\frac{C}{\alpha\left(\frac{1-\lambda}{\delta^{m}}-\frac{1}{\delta^{p}}\right)}
$$

Na segunda etapa da derivação, quando há incerteza sobre o fluxo de lucro futuro, a data de emissão é desconhecida. A função objetivo do empreendedor, dada pela equação (1), é reescrita sem o subscrito $t$ em $\pi$, já que o tempo não desempenha nenhum papel na análise. Na região de continuidade, descartando-se os termos de ordem $d t^{2}$ e superiores, essa equação pode ser reescrita como:

$$
\rho^{p} F(\pi) d t=\alpha \pi d t+E[d F(\pi) / \pi]
$$

Essa equação é uma condição de equilíbrio, na qual o retorno total esperado de manter o capital da empresa fechado $F(\pi)$ durante um pequeno intervalo de tempo $d t$, lado direito da equação, deve ser igual ao retorno exigido pelo proprietário da empresa, lado esquerdo. Como a incerteza sobre o valor de $F(\pi)$ é calibrada pela incerteza sobre os lucros $\pi$, em equilíbrio $F(\pi)$ deve possuir o mesmo retorno esperado do mercado financeiro $\rho^{m}$. Expandindo-se $d F(\pi)$ por Taylor, através do lema de Itô na equação (3), retirando-se as expectativas e cancelando-se os termos $d t$ 's, encontra-se a seguinte equação diferencial de segunda ordem:

$$
\frac{1}{2} \sigma^{2} \pi^{2} F^{\prime \prime}(\pi)+\left(\rho^{p}-\delta^{p}\right) \pi F^{\prime}(\pi)-\rho^{p} F(\pi)+\alpha \pi=0
$$

A solução para a equação diferencial de segunda ordem terá a seguinte forma:

$$
F(\pi)=A_{1} \pi^{\beta_{1}}+A_{2} \pi^{\beta_{2}}+\alpha \frac{\pi}{\delta^{p}}
$$

Os dois primeiros termos dessa equação são as soluções para a parte homogênea da equação com as seguintes raízes

$$
\left(\begin{array}{l}
\beta_{1} \\
\beta_{2}
\end{array}\right)=\frac{1}{2}-\frac{\left(\rho^{p}-\delta^{p}\right)}{\sigma^{2}} \pm \sqrt{\left[\frac{\left(\rho^{p}-\delta^{p}\right)}{\sigma^{2}}-\frac{1}{2}\right]^{2}+\frac{2 \rho^{p}}{\sigma^{2}}}<\left(\begin{array}{l}
1 \\
0
\end{array}\right), \mathrm{e}
$$

o terceiro termo é a integral particular de toda a equação. Para encontrar o valor crítico que induz o IPO, a equação (4) deve satisfazer as seguintes condições de contorno (Draho, 2000):

$$
\begin{aligned}
& F(0)=0, \\
& F\left(\pi^{*}\right)=\alpha \frac{\pi^{*}}{\delta^{m}}(1-\lambda)-C, \\
& F^{\prime}\left(\pi^{*}\right)=\frac{(1-\lambda)}{\delta^{m}}
\end{aligned}
$$

A primeira condição afirma que, se o valor da empresa é igual a zero, a opção de abrir o capital é inútil. As condições seguintes são, respectivamente, o valor indiferente (value-matching), no qual o empreendedor é indiferente entre continuar e parar, e o valor de passagem, em que, para cada $t$, as funções $F(\pi)$ e $\Omega(\pi)$ se tangenciam (smooth pasting).

Desde que $\beta_{2}<0$ e a condição de contorno $F(0)=0$ mantenham-se, então, $A_{2}=0$. Se esse não fosse o caso, Draho (200o) argumenta que o valor da opção explodiria: $\pi$ passaria de zero, o que violaria a condição de contorno. Portanto, o valor da empresa para o empresário, com a opção de timing, é $F(\pi)=A_{1} \pi^{\beta_{1}}+\frac{\alpha \pi}{\delta^{p}}$, onde $A_{1} \pi^{\beta_{1}}$ é o valor da opção de timing. 
O valor da opção é encontrado substituindo-se $F(\pi)$ na condição de contorno smooth pasting, obtendo-se $A_{1} \pi^{\beta_{1}}=\left(\frac{\pi^{*}}{\beta_{1}}\right) \alpha\left(\frac{1-\lambda}{\delta^{m}}-\frac{1}{\delta^{p}}\right)$. Assim, substituindo esse valor na condição de contorno do value-matching, obtém-se o seguinte nível crítico de lucro para o caso dos lucros estocásticos:

$$
\pi^{*}=\left(\frac{\beta_{1}}{\beta_{1}-1}\right) \frac{C}{\alpha\left(\frac{1-\lambda}{\delta^{m}}-\frac{1}{\delta^{p}}\right)}=\left(\frac{\beta_{1}}{\beta_{1}-1}\right) \pi^{n}
$$

onde

$$
\begin{aligned}
& \beta_{1}=\frac{1}{2}-\frac{\left(\rho^{p}-\delta^{p}\right)}{\sigma^{2}}+\sqrt{\left(\frac{\left(\rho^{p}-\delta^{p}\right)}{\sigma^{2}}-\frac{1}{2}\right)^{2}+\frac{2 \rho^{p}}{\sigma^{2}}}>1 \\
& \text { e } A_{1}=\frac{\left(\beta_{1}-1\right)^{\beta_{1}-1}}{\beta_{1}^{\beta_{1}}}\left(\frac{1-\lambda}{\delta^{m}}-\frac{1}{\delta^{p}}\right)^{\beta_{1}} \frac{\alpha^{\beta_{1}}}{C^{\beta_{1}-1}} .
\end{aligned}
$$

Concluindo, ao abrir o capital, o empreendedor sacrifica a oportunidade de fazer um IPO em períodos posteriores, quando as condições do mercado podem ser mais favoráveis. Para compensar essa perda, o empresário deve receber um benefício ao abrir o capital que é significativamente maior do que a avaliação privada. Dessa maneira, o valor crítico de se fazer um IPO é equivalente a um preço de exercício da opção de timing. Ainda, introduzindo a opção de timing, cria-se um custo adicional de se fazer um IPO imediatamente, além dos custos de emissão, que deve ser considerado como um custo de oportunidade derivado da decisão da abertura do capital. Assim, ao considerar a opção de timing, a empresa realiza um IPO quando a seguinte

restrição é satisfeita, $\underbrace{\alpha \frac{\pi}{\delta^{m}}(1-\lambda)-C}_{\Omega(\pi)}-\underbrace{\frac{\alpha \pi}{\delta^{p}}-A_{1} \pi^{\beta_{1}}}_{F(\pi)}>0$ ou seja, quando $\Omega(\pi)>\alpha \underbrace{v^{p}}_{\begin{array}{c}\text { valorda } \\ \text { empresa }\end{array}}+\underbrace{A_{1} \pi^{\beta_{1}}}_{\begin{array}{c}\text { valorda } \\ \text { opcaio }\end{array}}$.

Na sequência, Bouis (2003) aprimora o modelo anterior acrescentando à análise dois tipos de investidores. Os investidores racionais, que financiam o capital inicial da empresa e são os agentes econômicos que tomam a decisão de realizar o IPO (capitalistas de risco), e os investidores otimistas (investidores externos), que compram as participações no capital ofertadas no mercado acionário e apresentam divergências, em relação aos racionais, quanto ao valor da empresa. Assim, esse autor adiciona outra fonte de incerteza ao modelo que é o preço das ações no mercado secundário em momento posterior ao IPO, a ser determinado pelo número de investidores otimistas.

Intuitivamente, Bouis (2003) explica que o capital de risco vai tomar a decisão de realizar o IPO da empresa quando o fluxo de lucro for baixo ou quando o número de investidores otimistas for elevado. Isso significa que as empresas deveriam abrir seu capital quando o subapreçamento (underpricing) médio for alto. Portanto, o capital de risco exerce a opção de IPO, especialmente, após um choque positivo sobre o número de investidores otimistas, ou seja, num mercado quente (hot market). Esse modelo fornece uma explicação para a causalidade positiva observada entre retornos médios iniciais e o volume de ações ofertadas no mercado secundário.

\section{3_Metodologia}

Para verificar se as decisões de IPO das empresas brasileiras de energia, durante o período de 2000 a 2009 , foram determinadas (ou tomadas) segundo descrito pelo modelo de Draho (200o), comparam-se os níveis de lucro crítico $\left(\pi^{*}\right)$ das empresas ofertantes, determinados conforme as 
equações de Draho (200o), com o nível de lucro efetivo trimestral $^{10}$ das empresas $\left(\pi^{e}\right)$ na seguinte condição: no momento da decisão efetiva pela venda das ações, ou seja, na data do registro da oferta. Esse tipo de comparação é possível, pois Draho (200o) argumenta que não importa de quais valores partam os parâmetros do lucro crítico, visto que a simulação levará sempre a uma trajetória ótima.

É importante ressaltar que, como não se está utilizando um teste de hipótese segundo os cânones de inferência estatística, a comparação determinística sempre levará à rejeição de Ho em todos os casos em que o lucro crítico não for exatamente igual ao lucro efetivo. O objetivo, portanto, é verificar tão somente se a diferença é economicamente relevante, ou seja, se o custo de oportunidade de espera $\mathrm{C}^{\mathrm{e}}$ (quando o lucro atinge o ponto ótimo, segundo Draho (2000), e é descontado a valor presente até a data efetiva do IPO) é relevante. Caso tal diferença seja economicamente relevante, indicará que o modelo de Draho (2000) desconsidera variáveis utilizadas pelas empresas de energia que tomaram a decisão de realizar o IPO no período de análise.

Durante o período de 2000-2009, foram registradas na Comissão de Valores Mobiliários (CVM) nove ofertas de empresas de energia. A Novamarlim Participações S.A. registrou a abertura do seu capital em 2001; suas principais atividades são a compra, a venda e a importação de equipamentos para a produção e comercialização de petróleo. No terceiro trimestre de 2004, a CPFL Energias S.A. registrou o lançamento do seu IPO; suas atividades são a distribuição, a geração e a comercialização de energia elétrica no Brasil, nos mercados regulado e livre. No terceiro trimestre de 2005, a EDP Energias do Brasil S.A. registrou a abertura do seu capital; suas atividades concentram-se na distribuição, na geração e na comercialização de energia elétrica no Brasil. Também, no quarto trimestre de 2005, a Cosan S.A. Indústria e Comércio registrou o lançamento da sua oferta pública; seu negócio é a produção e a distribuição de energia limpa (etanol), principalmente através da cana-de-açúcar. No quarto trimestre de 2006, a Brasil Ecodiesel Indústria e Comércio de Biocombustíveis e Óleos Vegetais S.A. registrou sua oferta pública primária; sua atividade é a comercialização e a exportação de produtos agrícolas, especialmente oleaginosas e seus subprodutos, produção e transformação de óleos vegetais e produtos derivados em combustível vegetal (biocombustível).

Em 2007, três empresas abriram o capital. A primeira foi a São Martinho S.A., que, no primeiro trimestre de 2007, registrou seu IPO; essa empresa tem como atividade preponderante o plantio de cana-de-açúcar e a fabricação e o comércio de açúcar, álcool e demais derivados da cana-de-açúcar, cogeração de energia elétrica, exploração agrícola e pecuária. Em seguida, a Açúcar Guarani S.A. registrou o lançamento do seu IPO no terceiro trimestre de 2007; possui como atividades principais o plantio de cana-de-açúcar e a fabricação e comércio de açúcar, etanol e demais derivados da cana-de-açúcar, a exploração agrícola e a geração e comércio de energia. No quarto trimestre de 2007, a MPX Energia S.A. registrou a abertura de seu capital; possui atividade preponderantemente na geração de energia através do desenvolvimento de matrizes energéticas diversificadas, como carvão mineral, gás natural e fontes renováveis. A OGX Petróleo e Gás Participações S.A. registrou seu IPO no segundo trimestre de 2008; seu negócio concentra-se na exploração e na produção de petróleo e gás natural, nas bacias de Santos, Campos, Espírito Santo e Pará-Maranhão.

Entretanto, em 21/7/2010, a Novamarlim Participações S.A. fechou seu capital e, assim, foi excluída da amostra por falta de dados. Dessa maneira, a análise sobre a decisão do IPO se concentrou somente em oito empresas de energia: CPFL, EDP, Cosan, Brasil Ecodiesel, São Martinho, Açúcar Guarani, MPX e OGX. 
Para determinar os parâmetros utilizados na equação do lucro crítico dessas empresas, foram coletadas as seguintes variáveis:

- taxa de juros Selic mensal, obtida pela fonte primária Banco Central do Brasil através do site da Receita Federal (http://www.receita.fazenda.gov.br);

- índice de energia elétrica ${ }^{11}$ (IEE) e índice Bovespa ${ }^{12}$ (IBOV) mensais, coletados da fonte primária BM\&FBOVESPA pelo site (http://www.bmfbovespa. com.br). Considerando-se que as oito empresas da amostra possuem relação com o segmento de energia elétrica (seja através da produção direta de hidroeletricidade, seja através da produção de fontes alternativas de energia que comporão a matriz energética brasileira em complemento à fonte hidroelétrica, quais sejam, biocombustíveis e combustíveis de origem fóssil), utilizou-se o índice de energia elétrica para capturar a volatilidade dos empreendimentos ligados a esse setor;

- beta alavancado (60 meses) das empresas da amostra, coletado da fonte primária BM\&FBOVESPA, através do software da empresa Economática; PIB trimestral da indústria de energia elétrica, gás e água, obtido da fonte primária Instituto Brasileiro de Geografia e Estatística, Sistema de Contas Nacionais Trimestrais Referência 2000 (IBGE/ SCN 2000 Trimestral), através do site do Ipeadata (http://www.ipeadata.gov.br).

- prospectos definitivos de emissão das empresas, obtidos da CVM, por meio do site (http://www.cvm. gov.br). Esse prospecto contém informações sobre a oferta pública inicial das empresas. Além disso, esse site contém informações periódicas sobre os níveis de lucro trimestral e anual efetivo das empresas (ITR e DFP - Demonstração do Resultado do Exercício Trimestral e Anual), necessário para a comparação determinística.

O Quadro 1 descreve o cálculo (trimestral) das variáveis utilizadas no cálculo do lucro crítico $\left(\pi^{*}\right)$ que induz o IPO de acordo com o modelo pioneiro de Draho (2000).

Merece menção o cálculo de $\rho^{p}$, proxy desenvolvida no trabalho que considera a taxa de retorno do empreendedor não diversificado a partir do risco total do setor (variância), e não apenas do risco sistêmico (beta). Para evidenciar o risco total, utilizou-se a variação do índice de energia elétrica (IEE) em relação ao mercado (Ibovespa), e não a covariância desse índice com o mercado. Ou seja, para o risco total, não foram considerados os efeitos da diversificação que reduzem a variância da carteira ao seu valor mínimo, dado pela covariância média de seus ativos (tal como utilizado no cálculo do beta). Já para a taxa de retorno do investidor diversificado $\rho^{m}$, a medida de risco utilizada foi o beta das empresas, que considera os benefícios da diversificação reduzindo o retorno exigido.

\section{4_Resultados}

As variáveis utilizadas para se obter o nível de lucro crítico das empresas foram calculadas, em base trimestral, até o trimestre anterior à data de protocolo da oferta de ações. A Tabela 1 apresenta os valores das variáveis necessárias ao modelo de Draho (2000) das oito empresas.

Pela tabela, nota-se que a hipótese principal do modelo de Draho (2000) $\rho^{p}>\rho^{m}>\mu>r$ é respeitada pela maioria das empresas. Também, observa-se que as duas empresas que apresentaram as maiores taxas de desconto do empreendedor $\left(\rho^{p}\right)$ foram a MPX e a OGX $(16,30 \% \mathrm{e}$ $16,19 \%$, respectivamente) e as que apresentaram as menores taxas foram a Cosan e a São Martinho (7,45\% e 8,72\%, res- 
Quadro 1_Variáveis utilizadas no lucro crítico do modelo de Draho (valores trimestrais)

\begin{tabular}{|c|c|c|c|}
\hline Símbolo & Variável & Descrição & Fonte de Informações \\
\hline$\rho^{p}$ & Taxa de Desconto do Empreendedor & $r_{\substack{\text { trimestral } \\
\text { acumulado }}}+\frac{\operatorname{var}(I E E)}{\operatorname{var}(I B O V)} X\left(E(R m)-r_{\begin{array}{c}\text { trimestral } \\
\text { acumulado }\end{array}}\right)$ & $\begin{array}{l}\text { Banco Central do Brasil e } \\
\text { BM\&FBOVESPA }\end{array}$ \\
\hline$\rho^{m}$ & $\begin{array}{l}\text { Taxa de Desconto dos } \\
\text { Investidores Externos } \\
\text { (CAPM }{ }^{13} \text { ) }\end{array}$ & $\underset{\substack{\text { trimestral } \\
\text { acumulado }}}{r_{\text {empresaalavancado }}} X\left(E(R m)-r_{\begin{array}{c}\text { trimestral } \\
\text { acumulado }\end{array}}\right)$ & $\begin{array}{l}\text { Banco Central do Brasil, } \\
\text { Banco de Dados } \\
\text { Economática e } \\
\text { BM\&FBOVESPA }\end{array}$ \\
\hline$R$ & Taxa Livre de Risco & Taxa de Juros Selic & Banco Central do Brasil \\
\hline$\mu$ & Taxa Média de Crescimento do Setor & Média do PIB Industrial & \\
\hline$\sigma$ & Volatilidade do Setor & Desvio Padrão do PIB Industrial & 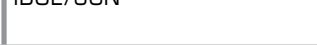 \\
\hline$\delta^{p}$ & Rendimento do Empreendedor & $\rho^{p}-\mu$ & \\
\hline$\delta^{m}$ & Rendimento dos Investidores Externos & $\rho^{m}-\mu$ & Iodas as fontes anterıores \\
\hline$\alpha$ & Fração do Capital Aberto & Free Float ${ }^{14}$ & \\
\hline$\lambda$ & Comissões de Subscrição & Total de Comissões & $\begin{array}{l}\text { Prospecto Defınitıvo de } \\
\text { Emissão da Empresa }\end{array}$ \\
\hline C & Custo Direto de Emissão & Total de Despesas & \\
\hline
\end{tabular}

Fonte: Elaboração própria.

Tabela 1_Variáveis necessárias ao modelo de Draho (2000)

\begin{tabular}{|c|c|c|c|c|c|c|c|c|}
\hline Variável & CPFL & EDP & Cosan & Brasil Ecodiesel & São Martinho & Açúcar Guarani & MPX & OGX \\
\hline$\rho^{p}$ & $14,46 \%$ & $12,91 \%$ & $7,45 \%$ & $8,89 \%$ & $8,72 \%$ & $9,51 \%$ & $16,30 \%$ & $16,19 \%$ \\
\hline$\rho^{m}$ & $5,41 \%$ & $5,56 \%$ & $5,17 \%$ & $5,54 \%$ & 4,62\% & $4,80 \%$ & $5,08 \%$ & $4,93 \%$ \\
\hline$\mu$ & $4,91 \%$ & $4,51 \%$ & $4,43 \%$ & $4,08 \%$ & $4,05 \%$ & $3,88 \%$ & $3,71 \%$ & $3,66 \%$ \\
\hline$R$ & $3,78 \%$ & $4,19 \%$ & $4,57 \%$ & $3,58 \%$ & $3,53 \%$ & $3,03 \%$ & $2,79 \%$ & $2,59 \%$ \\
\hline$\sigma$ & $12,76 \%$ & $11,70 \%$ & $11,47 \%$ & $10,71 \%$ & $10,53 \%$ & १०,२2\% & $9,99 \%$ & $9,72 \%$ \\
\hline$\delta^{p}$ & $9,55 \%$ & $8,39 \%$ & $3,02 \%$ & $4,80 \%$ & $4,67 \%$ & $5,63 \%$ & $12,59 \%$ & $12,53 \%$ \\
\hline$\delta^{m}$ & $0,50 \%$ & $1,04 \%$ & $0,74 \%$ & $1,46 \%$ & $0,57 \%$ & 0,92\% & $1,37 \%$ & $1,27 \%$ \\
\hline$\alpha$ & $10,52 \%$ & $27,44 \%$ & $26,29 \%$ & $27,70 \%$ & $16,70 \%$ & $32,50 \%$ & $26,28 \%$ & $38,73 \%$ \\
\hline$\lambda$ & $4,00 \%$ & $3,25 \%$ & $4,75 \%$ & $6,00 \%$ & $3,68 \%$ & $3,51 \%$ & $4,20 \%$ & $4,00 \%$ \\
\hline C & 9.410 .474 & 5.165 .740 & 7.641 .000 & 3.865 .740 & 3.885 .740 & 3.115 .740 & 9.307 .344 & 8.089 .970 \\
\hline
\end{tabular}

Fonte: Elaboração própria. 
pectivamente), indicando que as duas primeiras empresas têm incentivos a realizar o IPO mais rapidamente que as segundas. Tal se dá pelo fato de, nas primeiras, a não diversificação do empreendedor representar alto custo de oportunidade para a empresa, que tem seu valor de mercado privado extremamente reduzido por conta desse custo.

Para definição do timing ótimo do IPO, segundo Draho (2000), primeiramente se encontra o nível de lucro ingênuo $\left(\pi^{n}\right)$, ou seja, que não considera as incertezas sobre o fluxo futuro de lucro, através da seguinte equação:

$$
\pi^{n}=\frac{C}{\alpha\left(\frac{1-\lambda}{\delta^{m}}-\frac{1}{\delta^{p}}\right)} .
$$

Em seguida, considerando-se as incertezas sobre o fluxo de lucro, determina-se a raiz característica da equação diferencial $\left(\beta_{1}\right)$ e o lucro crítico que induz o $\operatorname{IPO}\left(\pi^{*}\right)$, através das seguintes equações:

$$
\beta_{1}=\frac{1}{2}-\frac{\left(\rho^{p}-\delta^{p}\right)}{\sigma^{2}}+\sqrt{\left(\frac{\left(\rho^{p}-\delta^{p}\right)}{\sigma^{2}}-\frac{1}{2}\right)^{2}+\frac{2 \rho^{p}}{\sigma^{2}}}>1
$$

e

$$
\pi^{*}=\left(\frac{\beta_{1}}{\beta_{1}-1}\right) \pi^{n} .
$$

A Tabela 2 mostra os resultados dos respectivos lucros e a raiz característica de cada empresa.

Observa-se que, ao adicionar a opção de timing ao valor privado da empresa, o nível de lucro crítico aumenta, ou seja, em todos os casos $\pi^{*}>\pi^{n}$, dado que $\left(\beta_{1}\right)$ é maior que 1 , mostrando que o exercício da opção de realizar o IPO é um custo de oportunidade do IPO.
Tabela 2_Resultados referentes ao modelo de Draho

\begin{tabular}{l|r|r|r} 
Empresa & \multicolumn{1}{l|}{$\pi^{n}$} & \multicolumn{1}{l}{$\beta_{1}$} & \multicolumn{1}{l}{$\pi^{*}$} \\
\hline CPFL & $\mathrm{R} \$ 492.777$ & 2,3 & $\mathrm{R} \$ 846.635$ \\
\hline EDP & $\mathrm{R} \$ 232.100$ & 2,3 & $\mathrm{R} \$ 401.949$ \\
\hline Cosan & $\mathrm{R} \$ 304.008$ & 1,5 & $\mathrm{R} \$ 852.850$ \\
\hline Brasil Ecodiesel & $\mathrm{R} \$ 320.452$ & 1,9 & $\mathrm{R} \$ 667.179$ \\
\hline São Martinho & $\mathrm{R} \$ 157.675$ & 1,9 & $\mathrm{R} \$ 330.238$ \\
\hline Açúcar Guarani & $\mathrm{R} \$ 110.044$ & 2,1 & $\mathrm{R} \$ 207.605$ \\
\hline $\mathrm{MPX}$ & $\mathrm{R} \$ 571.373$ & 3,3 & $\mathrm{R} \$ 815.412$ \\
\hline $\mathrm{OGX}$ & $\mathrm{R} \$ 320.882$ & $\ldots, 3$ & $\mathrm{R} \$ 455.537$
\end{tabular}

Fonte: Elaboração própria.

Para verificar se as empresas de energia tomaram a decisão de realizar o IPO conforme definido pelo modelo de Draho (2000), buscou-se na CVM os lucros efetivos acumulados trimestrais $\left(\pi^{e}\right)$ das empresas nos trimestres que antecederam o trimestre de registro do IPO e fez-se uma comparação desses com o nível de lucro crítico do modelo $\left(\pi^{*}\right)$.

Pelas informações da Tabela 3, a CPFL realizou o IPO no terceiro trimestre de 2004, quando seu lucro acumulado trimestral era de $\mathrm{R} \$ 118.835$, diferentemente do nível de lucro calculado pelo modelo, de $\mathrm{R} \$ 846.635$ (esse nível de lucro só foi atingido no quarto trimestre de 2005: $\mathrm{R} \$ 1.021 .278$ ). Mesmo descontando o custo de oportunidade de espera ( $\mathrm{R} \$ 1.021 .278$ descontado pela taxa de juros até a data do IPO), chega-se a um lucro de R $\$ 847.653$, bastante superior ao nível de lucro observado no momento do IPO.

Na Tabela 4, verifica-se que a EDP realizou sua oferta pública primária no terceiro trimestre de 2005, quando seu lucro foi de $\mathrm{R} \$ 284.089$, diferentemente do nível de lucro crítico estimado pelo modelo, de R 401.949 (esse nível só foi atingido no quarto trimestre de 2005: R\$ 439.406). Ao descontar o custo de oportunidade de espera ( $R \$ 439.406$ descontado pela taxa de juros até a data do IPO), chega-se 
Tabela 3_Comparação com o nível de lucro acumulado efetivo da CPFL

\begin{tabular}{|c|c|c|c|c|}
\hline $\begin{array}{l}\text { Valor Acumulado } \\
\text { do Atual } \\
\text { Exercício }\end{array}$ & $\begin{array}{l}1^{\circ} \text { trimestre } \\
1^{\circ} / 1 \text { a } 31 / 3\end{array}$ & $\begin{array}{l}2^{\circ} \text { trimestre } \\
1^{\circ} / 1 \text { a } 30 / 6\end{array}$ & $\begin{array}{l}3^{\circ} \text { trimestre }^{15} \\
1^{\circ} / 1 \text { a } 30 / 9\end{array}$ & $\begin{array}{l}4^{0} \text { trimestre }^{16} \\
1^{\circ} / 1 \text { a } 31 / 12\end{array}$ \\
\hline २००३ & $R \$-240.839$ & $R \$-326.881$ & $R \$-389.918$ & R\$-297.392 \\
\hline 2004 & $R \$-11.959$ & $\mathrm{R} \$ 124.826$ & R\$ 118.835 & R\$278.919 \\
\hline 2005 & $\mathrm{R} \$ 165.646$ & $\mathrm{R} \$ 400.597$ & $R \$ 640.561$ & $\mathrm{R} \$ 1.021 .278$ \\
\hline 2006 & $\mathrm{R} \$ 306.488$ & $\mathrm{R} \$ 611.981$ & $\mathrm{R} \$ 1.058 .742$ & $\mathrm{R} \$ 1.404 .096$ \\
\hline 2007 & R\$ 472.928 & R\$ 842.375 & $\mathrm{R} \$ 1.270 .814$ & $\mathrm{R} \$ 1.640 .727$ \\
\hline 2008 & R\$ 265.332 & R\$ 591.920 & R\$ 935.808 & $\mathrm{R} \$ 1.275 .692$ \\
\hline 2009 & $\mathrm{R} \$ 264.708$ & $\mathrm{R} \$ 674.028$ & $\mathrm{R} \$ 1.122 .793$ & $\mathrm{R} \$ 1.688 .868$ \\
\hline 2010 & $\mathrm{R} \$ 487.863$ & R\$ 847.633 & $\mathrm{R} \$ 1.198 .414$ & $\mathrm{R} \$ 1.560 .037$ \\
\hline \multicolumn{5}{|c|}{$\pi^{e}=\mathrm{R} \$ 118.835$} \\
\hline \multicolumn{5}{|c|}{$\pi^{*}=\mathrm{R} \$ 846.635$} \\
\hline
\end{tabular}

Fonte: Elaboração própria, com dados da CVM.

ao valor de $\mathrm{R} \$ 407.682$, muito acima do nível de lucro observado no período em que o IPO foi realizado.

Pelas informações da Tabela 5, a Cosan realizou seu IPO no quarto trimestre de 2005, quando seu lucro foi de R\$64.562, isto é, muito diferente do nível de lucro crítico calculado pelo modelo de Draho (2000), de R $\$ 852.850$ (esse valor só foi atingido no quarto trimestre de 2009: $\mathrm{R} \$ 1.047 .550)$. Ao descontar o custo de oportunidade de espera ( $\mathrm{R} \$ 1.047 .550$ descontado pela taxa de juros até a data do IPO), chega-se a um nível de lucro de $\mathrm{R} \$ 519.956$, ainda muito superior ao nível de lucro no qual o IPO foi realizado.

Na Tabela 6, observa-se que a Brasil Ecodiesel realizou o IPO no quarto trimestre de 2006, quando seu lucro foi de $\mathrm{R} \$$-38.086, muito inferior ao nível de lucro crítico estimado pelo modelo, de R \$667.179. Esse nível de lucro efetivo ainda não havia sido atingido pela empresa até o 4T2010.
Tabela 4_Comparação com o nivel de lucro acumulado efetivo da EDP

\begin{tabular}{|c|c|c|c|c|}
\hline $\begin{array}{l}\text { Valor Acumulado } \\
\text { do Atual } \\
\text { Exercício }\end{array}$ & $\begin{array}{l}1^{\circ} \text { trimestre } \\
1^{\circ} / 1 \text { a } 31 / 3\end{array}$ & $\begin{array}{l}2^{0} \text { trimestre } \\
1^{\circ} / 1 \text { a } 30 / 6\end{array}$ & $\begin{array}{l}3^{\circ} \text { trimestre } \\
1^{\circ} / 1 \text { a } 30 / 9\end{array}$ & $\begin{array}{l}4^{\circ} \text { trimestre } \\
1^{\circ} / 1 \text { a } 31 / 12\end{array}$ \\
\hline 2004 & - & $\mathrm{R} \$ 70.504$ & $\mathrm{R} \$ 69.958$ & R\$ 106.875 \\
\hline 2005 & $\mathrm{R} \$ 31.402$ & R\$ 229.479 & $\mathrm{R} \$ 284.086$ & $\mathrm{R} \$ 439.406$ \\
\hline 2006 & R\$ 99.284 & $\mathrm{R} \$ 125.353$ & $\mathrm{R} \$ 239.347$ & $\mathrm{R} \$ 394.120$ \\
\hline 2007 & $\mathrm{R} \$ 127.950$ & $\mathrm{R} \$ 240.837$ & $\mathrm{R} \$ 371.450$ & $\mathrm{R} \$ 450.444$ \\
\hline 2008 & $\mathrm{R} \$ 166.410$ & $\mathrm{R} \$ 166.917$ & $\mathrm{R} \$ 288.404$ & $\mathrm{R} \$ 388.779$ \\
\hline 2009 & $\mathrm{R} \$ 116.190$ & $\mathrm{R} \$ 348.563$ & $\mathrm{R} \$ 497.052$ & $\mathrm{R} \$ 858.316$ \\
\hline 2010 & $\mathrm{R} \$ 172.973$ & $\mathrm{R} \$ 308.919$ & $\mathrm{R} \$ 381.879$ & $\mathrm{R} \$ 736.641$ \\
\hline \multicolumn{5}{|c|}{$\pi^{e}=\mathrm{R} \$ 284.089$} \\
\hline \multicolumn{5}{|c|}{$\pi^{*}=\mathrm{R} \$ 401.949$} \\
\hline
\end{tabular}

Fonte: Elaboração própria, com dados da CVM.

Tabela 5_Comparação com o nivel de lucro acumulado efetivo da Cosan

\begin{tabular}{|c|c|c|c|c|}
\hline $\begin{array}{l}\text { Valor Acumulado } \\
\text { do Atual } \\
\text { Exercício }\end{array}$ & $\begin{array}{l}1^{0} \text { trimestre } \\
1^{\circ} / 5 \text { a } 31 / 7\end{array}$ & $\begin{array}{l}2^{\circ} \text { trimestre } \\
1^{\circ} / 5 \text { a } 31 / 10\end{array}$ & $\begin{array}{l}3^{0} \text { trimestre } \\
1^{\circ} / 5 \text { a } 31 / 1\end{array}$ & $\begin{array}{l}4^{0} \text { trimestre } \\
1^{\circ} / 5 \text { a } 30 / 4\end{array}$ \\
\hline 2004 & $\mathrm{R} \$-29.883$ & $\mathrm{R} \$-7.755$ & $R \$-15.765$ & $\mathrm{R} \$ 17.102$ \\
\hline 2005 & $R \$-6.190$ & $\mathrm{R} \$-22.536$ & $R \$-63.694$ & $\mathrm{R} \$-64.562$ \\
\hline 2006 & $\mathrm{R} \$ 5.378$ & $\mathrm{R} \$ 129.135$ & $\mathrm{R} \$ 192.544$ & $\mathrm{R} \$ 357.269$ \\
\hline 2007 & $\mathrm{R} \$ 13.667$ & $\mathrm{R} \$ 28.890$ & $R \$-42.505$ & $\mathrm{R} \$-47.775$ \\
\hline 2008 & $R \$-58.143$ & $\mathrm{R} \$-438.814$ & $R \$-433.606$ & $R \$-473.836$ \\
\hline 2009 & $\mathrm{R} \$ 405.114$ & $\mathrm{R} \$ 576.974$ & $\mathrm{R} \$ 759.765$ & $\mathrm{R} \$ 1.047 .550$ \\
\hline 2010 & $\mathrm{R} \$ 414.000$ & $\mathrm{R} \$ 251.950$ & R\$ 290.647 & $\mathrm{R} \$ 776.562$ \\
\hline \multicolumn{5}{|c|}{$\pi^{e}=\mathrm{R} \$-64.562$} \\
\hline \multicolumn{5}{|c|}{$\pi^{*}=\mathrm{R} \$ 852.850$} \\
\hline
\end{tabular}

Fonte: Elaboração própria, com dados da CVM. 
Tabela 6_Comparação com o nível de lucro acumulado efetivo da Brasil Ecodiesel

\begin{tabular}{|c|c|c|c|c|}
\hline $\begin{array}{l}\text { Valor Acumulado } \\
\text { do Atual } \\
\text { Exercício }\end{array}$ & $\begin{array}{l}1^{\circ} \text { trimestre } \\
1^{\circ} / 1 \text { a } 31 / 3\end{array}$ & $\begin{array}{l}2^{\circ} \text { trimestre } \\
1^{\circ} / 1 \text { a } 30 / 6\end{array}$ & $\begin{array}{l}3^{\circ} \text { trimestre } \\
1^{\circ} / 1 \text { a } 30 / 9\end{array}$ & $\begin{array}{l}4^{\circ} \text { trimestre } \\
1^{\circ} / 1 \text { a } 31 / 12\end{array}$ \\
\hline 2006 & - & - & - & $\mathrm{R} \$-38.086$ \\
\hline 2007 & $\mathrm{R} \$-526$ & $R \$-14.401$ & $R \$-13.309$ & $R \$-45.981$ \\
\hline 2008 & $\mathrm{R} \$-20.765$ & $R \$-104.709$ & $R \$-133.970$ & $R \$-197.100$ \\
\hline 2009 & $\mathrm{R} \$-28.992$ & $\mathrm{R} \$-9.057$ & $R \$-5.565$ & $\mathrm{R} \$-34.878$ \\
\hline 2010 & $\mathrm{R} \$ 15.992$ & $\mathrm{R} \$ 23.539$ & $\mathrm{R} \$ 20.948$ & $R \$-22.910$ \\
\hline \multicolumn{5}{|c|}{$\pi^{e}=\mathrm{R} \$-38.086$} \\
\hline
\end{tabular}

Fonte: Elaboração própria, com dados da CVM.

Pelas informações da Tabela 7, a São Martinho abriu o capital no primeiro trimestre de 2007, quando seu lucro foi de R \$-11.592, muito inferior ao nível de lucro calculado pelo modelo, de R \$330.238. Esse nível de lucro efetivo ainda não havia sido atingido pela empresa até o 4T2010.

Tabela 7_Comparação com o nivel de lucro acumulado efetivo da São Martinho

\begin{tabular}{|c|c|c|c|c|}
\hline $\begin{array}{l}\text { Valor Acumulado } \\
\text { do Atual } \\
\text { Exercício }\end{array}$ & $\begin{array}{l}1^{0} \text { trimestre } \\
1^{\circ} / 5 \text { a } 31 / 7\end{array}$ & $\begin{array}{l}2^{\circ} \text { trimestre } \\
1^{\circ} / 5 \text { a } 31 / 10\end{array}$ & $\begin{array}{l}3^{\circ} \text { trimestre } \\
1^{\circ} / 5 \text { a } 31 / 1\end{array}$ & $\begin{array}{l}4^{\circ} \text { trimestre } \\
1^{\circ} / 5 \text { a } 30 / 4\end{array}$ \\
\hline 2005 & $R \$-2.433$ & $\mathrm{R} \$ 7.934$ & $\mathrm{R} \$ 14.767$ & R\$ 20.888 \\
\hline 2006 & $\mathrm{R} \$ 3.743$ & $\mathrm{R} \$ 46.080$ & $\mathrm{R} \$ 61.773$ & $\mathrm{R} \$ 67.005$ \\
\hline 2007 & $R \$-11.592$ & $\mathrm{R} \$-43.732$ & $\mathrm{R} \$-49.509$ & $\mathrm{R} \$-48.794$ \\
\hline 2008 & $R \$-26.230$ & $\mathrm{R} \$-68.658$ & $R \$-105.019$ & $\mathrm{R} \$-71.865$ \\
\hline 2009 & $\mathrm{R} \$ 28.866$ & $\mathrm{R} \$ 49.074$ & $\mathrm{R} \$ 72.173$ & $R \$ 105.998$ \\
\hline 2010 & R\$ 19.072 & $\mathrm{R} \$ 60.748$ & $R \$ 130.413$ & $\mathrm{R} \$ 142.288$ \\
\hline
\end{tabular}

$$
\begin{aligned}
& \pi^{e}=\mathrm{R} \$-11.592 \\
& \pi^{*}=\mathrm{R} \$ 330.238
\end{aligned}
$$

Fonte: Elaboração própria, com dados da CVM.
Na Tabela 8, verifica-se que a Açúcar Guarani realizou seu IPO no terceiro trimestre de 2007, quando seu lucro foi de $\mathrm{R} \$-42.523$, muito inferior ao nível de lucro crítico estimado pelo modelo, de R $\$ 207.605$. Esse nível de lucro efetivo ainda não havia sido atingido pela empresa até 0 4T2010.

Tabela 8_Comparação com o nível de lucro acumulado efetivo do

\begin{tabular}{|c|c|c|c|c|}
\hline $\begin{array}{l}\text { Valor Acumulado } \\
\text { do Atual } \\
\text { Exercício }\end{array}$ & $\begin{array}{l}1^{\circ} \text { trimestre } \\
1^{\circ} / 5 \text { a } 31 / 7\end{array}$ & $\begin{array}{l}2^{\circ} \text { trimestre } \\
1^{\circ} / 5 \text { a } 31 / 10\end{array}$ & $\begin{array}{l}3^{\circ} \text { trimestre } \\
1^{\circ} / 5 \text { a } 31 / 1\end{array}$ & $\begin{array}{l}4^{\circ} \text { trimestre } \\
1^{\circ} / 5 \text { a } 30 / 4\end{array}$ \\
\hline 2006 & - & - & - & $\mathrm{R} \$ 116.821$ \\
\hline 2007 & $R \$-38.851$ & $R \$-27.812$ & $R \$-42.523$ & $R \$-62.908$ \\
\hline २००८ & $\mathrm{R} \$-26.629$ & $\mathrm{R} \$-128.385$ & $\mathrm{R} \$-241.391$ & $\mathrm{R} \$-205.164$ \\
\hline 2009 & $\mathrm{R} \$ 14.314$ & $\mathrm{R} \$ 13.842$ & $\mathrm{R} \$ 15.685$ & $\mathrm{R} \$ 24.335$ \\
\hline
\end{tabular}
Açúcar Guarani

Fonte: Elaboração própria, com dados da CVM.

Pelas informações da Tabela 9, a MPX realizou seu IPO no quarto trimestre de 2007, quando seu lucro foi de $\mathrm{R} \$$ -104.139, muito inferior ao nível de lucro estimado pelo modelo, de $\mathrm{R} \$ 815.412$. Esse nível de lucro efetivo ainda não havia sido atingido pela empresa até o 4T2010.

\begin{tabular}{|c|c|c|c|c|}
\hline $\begin{array}{l}\text { Valor Acumulado } \\
\text { do Atual } \\
\text { Exercício }\end{array}$ & $\begin{array}{l}1^{\circ} \text { trimestre } \\
1^{\circ} / 1 \text { a } 31 / 3\end{array}$ & $\begin{array}{l}2^{\circ} \text { trimestre } \\
1^{\circ} / 1 \text { a } 30 / 6\end{array}$ & $\begin{array}{l}3^{\circ} \text { trimestre } \\
1^{\circ} / 1 \text { a } 30 / 9\end{array}$ & $\begin{array}{l}4^{\circ} \text { trimestre } \\
1^{\circ} / 1 \text { a } 31 / 12\end{array}$ \\
\hline 2006 & $R \$-389$ & $R \$-1.020$ & $R \$-1.361$ & $R \$-1.789$ \\
\hline 2007 & $R \$-655$ & $\mathrm{R} \$-1.543$ & $\mathrm{R} \$-4.786$ & $R \$-104.139$ \\
\hline 2008 & $\mathrm{R} \$ 24.945$ & $\mathrm{R} \$ 54.226$ & $\mathrm{R} \$ 82.513$ & $\mathrm{R} \$ 204.129$ \\
\hline 2009 & $\mathrm{R} \$ 10.127$ & $\mathrm{R} \$-71.061$ & $R \$-162.350$ & R\$-220.183 \\
\hline 2010 & $\mathrm{R} \$-96.780$ & $R \$-165.402$ & $\mathrm{R} \$-247.245$ & R\$ -225.614 \\
\hline \multicolumn{5}{|c|}{$\pi^{e}=\mathrm{R} \$-104.139$} \\
\hline
\end{tabular}

Tabela 9_Comparação com o nível de lucro acumulado efetivo da MPX

Fonte: Elaboração própria, com dados da CVM. 
Na Tabela 10, a OGX abriu o capital no segundo trimestre de 2008 , quando seu lucro foi de $\mathrm{R} \$-78.343$, muito inferior ao nível de lucro calculado pelo modelo, de $\mathrm{R} \$ 438.600$. Esse nível de lucro efetivo ainda não havia superado o nível de lucro crítico até o 2T2010.

Tabela 10_Comparação com o nivel de lucro acumulado efetivo da OGX

\begin{tabular}{l|r|r|r|r}
$\begin{array}{l}\text { Valor Acumulado } \\
\text { do Atual } \\
\text { Exercicio }\end{array}$ & $\begin{array}{l}1^{\circ} \text { trimestre } \\
1 \% / 1 \text { a } 31 / 3\end{array}$ & $\begin{array}{l}2^{\circ} \text { trimestre } \\
1^{\circ} / 1 \text { a } 30 / 6\end{array}$ & $\begin{array}{l}3^{\circ} \text { trimestre } \\
1^{\circ} / 1 \text { a } 30 / 9\end{array}$ & $\begin{array}{l}4^{\circ} \text { trimestre } \\
1^{\circ} / 1 \text { a } 31 / 12\end{array}$ \\
\hline 2007 & $\mathrm{R} \$-2.861$ & $\mathrm{R} \$-5.260$ & $\mathrm{R} \$-5.354$ & $\mathrm{R} \$ 12.453$ \\
\hline 2008 & $\mathrm{R} \$ 17.265$ & $\mathrm{R} \$-78.434$ & $\mathrm{R} \$ 169.220$ & $\mathrm{R} \$ 359.884$ \\
\hline 2009 & $\mathrm{R} \$ 118.899$ & $\mathrm{R} \$-58.628$ & $\mathrm{R} \$-119.256$ & $\mathrm{R} \$-100.626$ \\
\hline 2010 & $\mathrm{R} \$ 56.887$ & $\mathrm{R} \$ 114.677$ & $\mathrm{R} \$-84.792$ & $\mathrm{R} \$-135.525$ \\
\hline & $\pi^{e}=\mathrm{R} \$-78.434$ \\
\hline
\end{tabular}

Fonte: Elaboração própria, com dados da CVM.

Dessa maneira, verifica-se que todas as empresas de energia analisadas, de acordo com o modelo de Draho (2000), anteciparam o timing do seu IPO. Algumas empresas, como a CPFL e a Cosan, acabaram por atingir um nível de lucro, algum tempo depois, a partir do qual o IPO poderia trazer resultados mais vantajosos para a empresa, caso ela tivesse esperado, enquanto outras empresas ainda não atingiram tal nível de lucro. Interessante notar que todas as empresas que não atingiram o nível de lucro crítico, no momento do IPO, apresentaram nível de lucro negativo e realizaram a emissão no ano de 2007 ou próximo desse ano (fim de 2006 ou logo no início de 2008), período caracterizado como um hot market, indicando que as empresas poderiam estar aproveitando janelas de oportunidade (supervalorização do mercado) em vez de estarem avaliando oportunidades internas.

Tal observação leva à necessidade de uma análise complementar entre o valor líquido efetivo obtido com o IPO (receita de IPO menos os custos totais) e o valor justo desse IPO calculado através da seguinte equação

$\Omega\left(\pi_{t}\right)=\alpha \frac{\pi_{t}}{\delta^{m}}(1-\lambda)-C$.

A Tabela 11 demonstra a diferença entre os valores.

Pela diferença relevante observada na última coluna da tabela, nota-se que uma das razões para que todas as empresas antecipassem o timing da abertura de capital pode

Tabela 11_Comparação entre o valor líquido real e o valor justo de IPO (em mil)

\begin{tabular}{|c|c|c|c|c|c|}
\hline Empresas & Receita de IPO & Custo Total do IPO & Valor Líquido Real & Valor Justo & Diferença \\
\hline CPFL & R\$ 820.962 & $\mathrm{R} \$ 42.125$ & $\mathrm{R} \$ 778.836$ & $\mathrm{R} \$ 7.690$ & $\mathrm{R} \$ 771.146$ \\
\hline EDP & $\mathrm{R} \$ 1.184 .702$ & $\mathrm{R} \$ 19.773$ & $\mathrm{R} \$ 1.164 .929$ & $\mathrm{R} \$ 5.094$ & $\mathrm{R} \$ 1.159 .834$ \\
\hline Cosan & $\mathrm{R} \$ 885.767$ & $\mathrm{R} \$ 44.227$ & $\mathrm{R} \$ 841.540$ & $\mathrm{R} \$ 21.219$ & $\mathrm{R} \$ 820.321$ \\
\hline Brasil Ecodiesel & $\mathrm{R} \$ 378.932$ & $\mathrm{R} \$ 26.601$ & $\mathrm{R} \$ 352.330$ & $\mathrm{R} \$ 8.032$ & $\mathrm{R} \$ 344.297$ \\
\hline São Martinho & $\mathrm{R} \$ 423.680$ & $\mathrm{R} \$ 3.885$ & $\mathrm{R} \$ 419.794$ & $\mathrm{R} \$ 5.433$ & $\mathrm{R} \$ 414.360$ \\
\hline Açúcar Guarani & $\mathrm{R} \$ 665.758$ & $\mathrm{R} \$ 26.503$ & $\mathrm{R} \$ 639.254$ & $\mathrm{R} \$ 3.960$ & $\mathrm{R} \$ 635.294$ \\
\hline MPX & $\mathrm{R} \$ 2.035 .409$ & $\mathrm{R} \$ 89.057$ & $\mathrm{R} \$ 1.946 .351$ & $\mathrm{R} \$ 5.677$ & $\mathrm{R} \$ 1.940 .674$ \\
\hline OGX & $\mathrm{R} \$ 6.711 .662$ & R\$ 242.997 & $\mathrm{R} \$ 6.468 .665$ & $\mathrm{R} \$ 4.750$ & $\mathrm{R} \$ 6.463 .914$ \\
\hline
\end{tabular}

Fonte: Elaboração própria, com dados do Anúncio de Encerramento das empresas. 
ter sido uma janela de oportunidade (presença de muitos investidores otimistas), conforme a descrita no modelo de Bouis (2003).

No modelo de Draho (2000), a janela de oportunidade ocorre quando há aumento anormal nos valores de mercado das empresas de determinado setor. Esse aumento anormal é suposto pela premissa de mercado incompleto, na qual os investidores externos atribuem às empresas de capital fechado um valor maior que aquele conferido pelo empreendedor à própria empresa, uma vez que o empreendedor concentra toda a sua riqueza na companhia, possuindo riscos privados (diversificáveis) e sistêmicos (não diversificáveis), ao passo que os investidores externos diversificam seus investimentos e carregam apenas riscos sistêmicos. Já no modelo de Bouis (2003), a janela de oportunidade acontece por causa da mudança de sentimento dos investidores otimistas (irracionais) que valorizam as empresas acima do valor considerado pelos investidores racionais (capital de risco) que estão na administração da empresa. Dessa maneira, a janela de oportunidade pode ocorrer por duas razões: não diversificação do empreendedor privado ou assimetria de informação.

Com a intenção de iniciar uma investigação sobre a janela de oportunidade ocorrida no ano de 2007, ou próximo dele, foi feita uma pesquisa suplementar sobre as características das ofertas públicas primárias das empresas, identificando se havia presença da capital de risco na administração da empresa antes do IPO e se a quantidade de investidores otimistas participando da oferta (investidores externos) era grande. Para tanto, verificou-se nos prospectos de emissão e no anúncio de encerramento de distribuição primária se existiam tais tipos de investidores. Foi dado destaque aos investidores racionais que detinham participação conjunta no capital acima de $60 \%$.
- Na CPFL observou-se que o capital social total era composto de $95 \%$ de capital de risco: VBC Energia ${ }^{17}$ (44\%), 521 Participações $^{18}$ (36\%) e Bonaire ${ }^{19}$ (15\%).

Entre os tipos de investidores interessados na oferta, a maioria era representada por pessoas físicas (2.661), ou seja, investidores otimistas.

- Na EDP, verificou-se que o capital social total era composto de 66\% de capital de risco: Energias de Portugal $^{20}(24 \%)$, Balwerk Consultoria ${ }^{21}(23 \%)$ e Eletricidade de Portugal Internacional ${ }^{22}$ (19\%). Dentre os tipos de investidores interessados na oferta, os acionistas iniciais eram a maioria (624), ou seja, investidores racionais.

- $\mathrm{Na}$ Cosan, notou-se que o capital social total era composto de 79\% de capital de risco: Aguassanta Participações ${ }^{23}$ (57\%) e Usina Costa Pinto S.A. Açúcar e Álcool ${ }^{24}$ (22\%). Entre os tipos de investidores interessados na oferta, as pessoas físicas eram a maioria (8.835), ou seja, investidores otimistas.

- $\mathrm{Na}$ Brasil Ecodiesel, observou-se que o capital social total era composto de $73 \%$ de capital de risco: Eco Green Solutions LLC ${ }^{25}$ (47\%) e Zartman Services LLC ${ }^{26}$ (26\%). Entre os tipos de investidores interessados na oferta, as pessoas físicas eram a maioria (9.315).

- Na São Martinho, verificou-se que o capital social total era composto de $68 \%$ de capital de risco: Luiz Ometto Participações ${ }^{27}$ (28\%), João Ometto Participações ${ }^{28}$ (28\%) e Nelson Ometto Participações ${ }^{29}(12 \%)$. Entre os tipos de investidores interessados na oferta, as pessoas físicas eram a maioria (24.369).

- Na Açúcar Guarani, notou-se que o capital social total era composto de $87 \%$ de capital de risco: $\operatorname{Tereos}^{30}(75 \%)$ e Tereos do Brasil Participações ${ }^{31}$ 
(12\%). Entre os tipos de investidores interessados na oferta, as pessoas físicas eram a maioria (12.229).

- Na MPX, verificou-se que não havia diluição do capital, uma vez que o empreendedor (Eike Batista) possuía cerca de $100 \%$ do capital social total. Entre os tipos de investidores interessados na oferta, as pessoas físicas eram a maioria (148).

- Na OGX, observou-se que o capital social total era composto de $72 \%$ de capital de risco: Centennial Asset Mining Fund LLC. ${ }^{32}$ Entre os tipos de investidores interessados na oferta, as pessoas físicas eram a maioria (1.308).

Portanto, observou-se, como característica comum, a presença de capital de risco na estrutura de capital de todas as empresas e de muitos investidores otimistas (pessoas físicas) interessados nos IPOs na maioria das empresas, o que mostra que a janela de oportunidade pode ter sido ocasionada pela divergência de crenças dos investidores otimistas.

\section{5_Considerações finais}

No presente trabalho, investigou-se se as decisões de abertura de capital das empresas brasileiras de energia, durante 0 período de 2000 a 2009, foram determinadas com base no modelo de Draho (2000). Nesse modelo, o empreendedor observa as condições de mercado susceptíveis à realização do IPO, existindo como fonte de incerteza na avaliação do valor da empresa o fluxo de lucros futuros. Essa incerteza é modelada pelo processo estocástico MGB, e o melhor momento para a abertura é definido valendo-se da metodologia da TOR. Tal metodologia permite capturar flexibilidades gerenciais na tomada de decisão, presentes à medida que novas informações surgem, e a incerteza sobre as condições do mercado e o fluxo futuro de caixa são gradualmente mais bem compreendidos.
Como resultado, encontrou-se que todas as empresas estudadas anteciparam o timing da sua oferta pública inicial em relação ao preconizado pelo modelo de Draho (2000). Destaca-se que algumas empresas apresentaram, no momento da oferta, níveis de lucro negativo e realizaram a emissão no ano de 2007 ou próximo desse ano (fim de 2006 ou logo no início de 2008), período caracterizado como um hot market, indicando que as empresas poderiam estar aproveitando a janela de oportunidade existente no mercado naquele momento. Adicionalmente, tem-se que o período da amostra (anos de valorização da Bolsa de Valores brasileira, que antecederam a crise subprime deflagrada em 2008) pode ter também contribuído para tal resultado.

Isso levou a uma análise complementar entre o valor líquido efetivo de IPO (receita de IPO menos os custos totais) e o valor justo desse IPO (representado pela venda da empresa privada e da opção de espera associada). Evidenciou-se que todas as empresas analisadas apresentaram valor real de receita de IPO maior que o valor justo, indicando que a presença de uma janela de oportunidade, conforme descrita no modelo de Bouis (2003), pode ter sido uma razão para as antecipações dos timings em relação ao modelo de Draho (2000).

Com a intenção de iniciar uma investigação sobre tal janela, foi realizada uma análise suplementar sobre as características das ofertas públicas primárias das empresas com o objetivo de identificar a presença da capital de risco na administração da empresa antes do IPO (investidor racional) e se a quantidade de investidores pessoa física (otimistas) era grande no momento da oferta. Observou-se, como característica comum, a presença de capital de risco na estrutura de capital de todas as empresas e de muitos investidores otimistas (pessoas físicas) interessados nos IPOs na maioria das empresas, mostrando que a janela de oportunidade pode ter sido ocasionada pela divergência de crenças dos 
investidores otimistas. Somente no caso da EDP verificou-se que, entre os tipos de investidores interessados na oferta da empresa, os acionistas iniciais eram a maioria (investidores racionais). Apenas essa empresa realizou o IPO num nível de lucro próximo ao determinado pelo modelo de Draho (2000).

Dessa maneira, os resultados não foram ao encontro do preconizado por Draho (2000). Isso pode ter ocorrido por causa da omissão de variáveis relevantes no modelo de Draho (2000). Em trabalhos futuros, é sugerida a aplicação do modelo de timing de Bouis (2003), que adiciona o preço das ações no mercado secundário como fonte de incerteza sobre o valor da empresa, sendo que é o número de investidores otimistas a variável de incerteza.

Outra questão que limita o trabalho diz respeito aos dados setoriais, concentrados no setor de energia elétrica, que não representa integralmente os negócios das empresas da amostra, sendo suas atividades dispersas (como produção de açúcar). Assim, outro complemento interessante seria a aplicação do método em setores mais homogêneos, desde que haja uma amostra relevante de IPOs realizados em tal setor.

\footnotetext{
Notas

${ }^{1}$ Para entender como ocorre a venda de ações no Brasil, ver Instrução 400 da Comissões de Valores Mobiliários (CVM).

${ }^{2}$ Para uma suficiente revisão sobre o tema Estrutura de Capital, ver Harris e Raviv (1991).

${ }^{3}$ Para uma suficiente revisão sobre o tema Governança Corporativa, ver Shleifer e Vishny (1997).

${ }^{4}$ Os principais custos indiretos de colocação de ações no mercado
}

no caso de juros compostos; retornos normalmente

distribuídos, o que facilita a manipulação matemática; e valor de um determinado ativo não negativo, como ocorre com os preços de ativos.

${ }^{6}$ A exigência de que as taxas do empreendedor e do mercado $\left(\rho^{m}\right)$ sejam maiores que a taxa de crescimento dos lucros da empresa $(\mu)$ tem por objetivo viabilizar o desconto do fluxo perpétuo de lucros, obtido com base na fórmula da perpetuidade com crescimento:

$V P($ empres $a)=\frac{\text { Lucros em } t+1}{(\rho-\mu)}$.

${ }^{7} \mathrm{O}$ processo de Wiener é um processo contínuo constituído por três propriedades (Dixit; Pindyck, 1994; Hull, 2002): (1) é um processo de Markov, o que significa que somente o valor presente de uma variável é relevante para prever o seu futuro; (2) possui incrementos independentes, ou seja, a distribuição de probabilidades da variação do processo em um intervalo de tempo é independente de qualquer outro intervalo de tempo e (3) as variações desse processo, em um intervalo de tempo finito, seguem uma distribuição normal, com variância que cresce linearmente com o intervalo de tempo.

${ }^{8} A_{1}$ é uma constante a ser determinada e $\beta_{1}$ é uma constante conhecida que depende dos parâmetros $\sigma, \delta^{p} \mathrm{e} \rho^{p}$. Ambos serão explicados na metodologia.
${ }^{9}$ A equação de Bellman também é conhecida como equação fundamental da otimalidade ou equação de Hamilton-Jacobi-Bellman.

${ }^{10}$ Optou-se por uma análise trimestral, uma vez que as empresas de capital aberto divulgam seus resultados trimestralmente.

${ }^{11}$ Segundo a BM\&FBOVESPA, os índices setoriais têm o objetivo de oferecer uma visão segmentada do comportamento dos mercados de ações. Eles são constituídos pelas empresas abertas mais significativas de setores específicos, representando uma medida do comportamento agregado do segmento econômico considerado.

${ }^{12}$ De acordo a BM\&FBOVESPA, o Ibovespa é o mais importante indicador do desempenho médio das cotações do mercado de ações brasileiro. Sua relevância advém do fato de o Ibovespa retratar o comportamento dos principais papéis negociados na BM\&FBOVESPA e também de sua tradição, já que o índice mantém a integridade de sua série histórica e não sofreu modificações metodológicas desde sua implementação, em 1968.

${ }^{13}$ Taxa comumente usada como retorno justo (diversificado) de um investidor.

${ }^{14}$ Free float designa as ações que se encontram em circulação, ou seja, aquelas que estão à disposição para negociação 
no mercado, excluindo-se as pertencentes aos controladores e aquelas na tesouraria da companhia.

${ }^{15}$ As informações referentes $\operatorname{aos} 1^{\circ}, 2^{\circ}$ e $3^{\circ}$ trimestres foram retiradas do documento: ITR Demonstração do Resultado do Exercício Trimestral - divulgado no site da CVM.

${ }^{16}$ As informações referentes ao $4^{\circ}$ trimestre foram retiradas do documento: DFPs - Demonstração do Resultado do Exercício Anual divulgado no site da CVM.

${ }^{17}$ A VBC Energia é uma holding controlada por três companhias brasileiras: Votorantim Energia Ltda., Bradesplan Participações S.A. e Camargo Corrêa Energia S.A.

${ }^{18}$ A 521 Participações é uma companhia holding controlada pela PREVI, fundo de pensão mantido pelo Banco do Brasil S.A.

${ }^{19}$ A Bonaire é uma companhia holding controlada pela Mellon Energia São Paulo FIA.

${ }^{20}$ A Energias de Portugal é uma sociedade por ações constituída de acordo com as leis de Portugal.

${ }^{21}$ A Balwerk Consultadoria é uma sociedade constituída de acordo com as leis de Portugal, controlada pela EDP Participações SGPS S.A.

${ }^{22}$ A Eletricidade de Portugal Internacional, SGPS, S.A. é uma sociedade constituída de acordo com as leis de Portugal, ontrolada pela da Energias de Portugal.
${ }^{23}$ A Aguassanta Participações S.A. é uma companhia holding constituída pelos acionistas da Nova Celisa, São Francisco e Irmãos Franceschi.

${ }^{24}$ A Usina Costa Pinto S. A. Açúcar e Álcool é controlada diretamente pela Aguassanta e indiretamente pelo Sr. Rubens Ometto Silveira Mello.

${ }^{25}$ Eco Green Solutions LLC é uma sociedade holding, tendo como única sócia a trust BT Global Investments Fund ("Unit Trust”).

${ }^{26}$ A Zartman Services LLC é uma holding, cujo único acionista é o Sr. Evon Zartman.

${ }^{27}$ Luiz Ometto Participações S.A. é uma sociedade anônima com o objetivo de administrar bens próprios ou alheios; ter participação no capital social de outras empresas; e realizar incorporações e participações em empreendimentos.

${ }^{28}$ João Ometto Participações S.A. é uma sociedade anônima com o objetivo social de participar em outras companhias comerciais, industriais, agropecuárias ou civis.

${ }^{29}$ Nelson Ometto Participações S.A. é uma sociedade limitada que foi constituída para realizar a administração de bens próprios e a participação em outras sociedades.

30 A Tereos é formada por duas sociedades cooperativas, denominadas Union Sucre Éthanol e por Union des Planteurs de Betteraves à Sucre.

\author{
${ }^{31}$ Tereos do Brasil Participações \\ Ltda. é uma sociedade brasileira \\ limitada empresária que é \\ controlada diretamente pela S.A.S \\ Berneuil Participations. \\ ${ }^{32} \mathrm{O}$ Sr. Eike F. Batista detém \\ indiretamente $100 \%$ de \\ participação na Centennial \\ Asset Mining Fund LLC.
}


ALTI, A. IPO Market Timing.

Review of Financial Studies, v. 18, p. 1105-1138, 2005.

BEAULIEU, Marie-Claude.; SODJAHIN William R. When are announced initial public offerings completed?

Université Laval, 2008.

BENVENISTE, L. M.; BUSABA, W.; WILHELM, W. J. Information externalities and the role of underwriters in primary equity markets. Journal of Financial Intermediation, v. 11, p 61-86, 2002.

BLACK, B.; GILSON, R. Venture capital and the structure of capital markets: Banks versus stock markets. , v. $47, \mathrm{n} .3$, p. 243-277, 1998.

BOMFIM, Lívia Pontes de Miranda, MACAGNANI dos SANTOS, Carolina; PIMENTA

Jr, Tabajara. Processos de abertura de capital de empresas brasileiras em 2004 e 2005: Razões e percepções. Revista de Administração. São Paulo, v.42, n.4, p. 524-534, 2007.

BOUIS, R. Optimistic Investors, IPOs Cycle, and Real

Investment. CFS Working Paper $\mathrm{n}^{\circ}$. 47, 2003.

BRAU, James; FAWCETT, Stanley E. Initial public offerings: An analysis of theory and practice. The Journal of Finance, v. LXI, n. 1, 2006.
CASAGRANDE NETO, H.; SOUZA, L.; A. ROSSI, M. C. Abertura do capital de empresas no Brasil: Um enfoque prático. São Paulo: Atlas, 2000.

CASTRO, Nival de José de; BRANDÃO, Roberto. investment grade leverages power sector. Revista Brasil Energy, Ed. 409, p. 44, 2008.

COPELAND, T. TUFANO, P. A Real-world way to manage real options. Harvard Business Review, março, p. 90-99, 2004.

\section{CORWIN S. A.; SCHULTZ P.}

The role of IPO underwriting syndicates: Pricing, information production, and underwriter competition, Journal of Finance, v. 60, p. 443-486, 2005.

CVM - COMISSÃO DE VALORES MOBILIÁRIOS. Guia: Orientação para a abertura de capital de empresas. Disponível em: http:// www.cvm.gov.br>. Acesso em: jun. 2010.

DIXIT, A.; PINDYCK, R.

Investment under uncertainty. Princeton University Press,

Princeton, NJ, 1994.

DIXIT, A. K.; PINDYCK, R. S. The options approach to capital investment. Harvard Business Review, May-June, 1995.
DRAHO, J. The timing of initial public offerings: a Real option approach. Working Paper, Yale University, 2000.

DRAHO, J. The IPO decision: Why and how companies go public, MPG Books Ltd. Bodmin Cornwall, 2004.

GRENADIER S.; WANG, N. Investment under uncertainty and time-inconsistent preferences. Journal of Financial Economics, v. 84, 2, p. 2-39, 2007.

HARRIS, M. RAVIV, A. The Theory of Capital Structure. Journal of Finance, v. 46, n. 1, p. 297-355, 1991.

HULL, John C. Options, futures and other derivatives securities. Prentice Hall. Fifth Edition, 2002.

INSTITUTO BRASILEIRO DE GOVERNANCA CORPORATIVA IBGC. Uma década de governança corporativa: História do IBGC, marcos e lições da experiência. São Paulo: Saint Paul Editora, 2006.

IPEADATA. Disponível em: $<$ http://www.ipeadata.gov.br $>$. Acesso em: jun. 2010.

JAGGIA, S.; THOSAR, S. The medium-term aftermarket in high-tech IPOs: Patterns and implications. Journal of Banking and Finance, v. 28, p. 931-950, 2004.
JENSEN, M. C.; W. H. MECKLING. Theory of the firm: managerial behavior, agency costs and ownership structure. Journal of Financial Economics, v. 3, p. 305-360, 1976 .

KIM, W.; WEISBACH, M. Motivations for public equity offers: An international perspective. Journal of Financial Economics, n. 87, 281-307, 2008.

LEAL, Ricardo P. C. Por que há retornos anormais nas aberturas de capital? In: LEAL, R. P. C.; COSTA JR., N. C. A. da; LEMGRUBER, E. F. (Orgs.). Finanças Corporativas. São Paulo: Atlas, p. 119-130, 2001.

LEIS SOBRE OS PROCEDIMENTOS DE ABERTURA DE CAPITAL:

Lei no ${ }^{\circ} 6.385 / 76,6.404 / 76,9.249 / 95$, 9.457/97, e Instrução da CVM n ${ }^{\circ}$ 400 de 2003.

LJUNGQVIST; A; NANDA, V.; SINGH, R. Hot markets, investor sentiment, and IPO pricing. The Journal of Business, v. 79, p. 1667-1702, 2006.

LOUGHRAN, T.; RITTER, J. R. Why has underpricing changed over time? Financial Management, v. 33, p. 5-37, 2004.

LOWRY, M. Why does IPO volume fluctuate so much? Journal of Financial Economics, v. 67, p. 3-40, 2003. 
LUEHRMAN, T. A. Strategy as a portfolio of real options. Harvard Business Review, Sept./Oct., 1998.

MAUER, D.; L. SENBET. The effect of the secondary market on the pricing of initial public offerings: Theory and evidence. Journal of Financial and Quantitative Analysis, v. 27, p. 55-79, 1992.

MINISTÉRIO DA FAZENDA.

Disponível em: <http://www. receita.fazenda.gov.br $>$. Acesso: em: jun. 2010.

PAGANO, Marco; PANETTA, Fabio; ZINGALES, Luigi. Why do companies go public? An empirical analysis. Journal of Finance, v. 53, p. 27-64, 1998.

PEROTTI, Enrico C.; Von THADDEN, Ernst-Ludwig. Strategic transparency and informed trading: Will capital market integration force convergence of corporate governance? Journal of Financial and Quantitative Analysis, v. 38 , p. $61-86,2003$.

RAJAN, R. Insiders and outsiders: The choice between informed and arm's length debt. Journal of Finance, p. 1367-1400,1992.

RESOLUÇÃO CMN nº 2.690/2000, altera e consolida as normas que disciplinam a constituição, a organização e o funcionamento das Bolsas de Valores.

RITTER, Jay R. The long run performance of initial public offerings. Journal of Finance, v. 46, p. 3-27, 1991
ROCK, Kevin. Why new issues are underpriced. Journal of Financial Economics, 1986.

ROSSI Jr, José Luiz; MAROTTA, Marcelo. Equity market timing: Testando através de IPO no mercado brasileiro.

Revista Brasileira de Finanças, v. 8, n. 1, p. 85-101, 2010.

SAHLMAN, W. A. The structure and governance of venturecapital organizations. Journal of Financial Economics, v. 21, p. 473-521, 1990.

SCHULTZ Paul; Mir ZAMAN. Do the individuals closest to internet firms believe they are overvalued? Journal of Financial Economics, v. 59, p. 347-381, 2001.

SEPIN - Superintendência de Estatística, Pesquisa e Informação/SEPLAN. Disponível em: <http://www.seplan.go.gov. br>. Acesso em: ago. 2010.

SHLEIFER, A.; VISHNY, R. A survey of corporate governance. Journal of Finance, v. 52, n. 2, p. 737-783, 1997.

SMITH, J.; McCARDLE, K. Options in the real world: Lessons learned in evaluating oil and gas investments. Operations Research, v. 47, p. 1-15, 1999.

SUBRAHMANYAM, A.; $\mathrm{S}$. TITMAN. The going-public decision and the development of financial markets. Journal of Finance, v. 54, p. 1045-1082, 1999.
TRIGEORGIS, L.; SCHWARTZ,

E. S. Real options and

investment under uncertainty

Massachusetts Institute of

Technology. First edition, 2004.

ZINGALES, L. Insider ownership and the decision to go public.

Review of Economic Studies, v.

62, p. 425-448,1995.
E-mail de contato dos autores

fernandafinotti.perobelli@ufjf.edu.br

brandao@iag.puc-rio.br

taysoares@yahoo.com.br

Artigo recebido em abril de $2012 \mathrm{e}$ aprovado em abril de 2013 
